\title{
CORRIGENDUM
}

\section{MUC4 mucin-induced epithelial to mesenchymal transition: a novel mechanism for metastasis of human ovarian cancer cells}

\author{
MP Ponnusamy, I Lakshmanan, M Jain, S Das, S Chakraborty, P Dey and SK Batra
}

Oncogene (2010) 29, 6084; doi:10.1038/onc.2010.472

Correction to: Oncogene (2010) 29, 5741-5754; doi:10.1038/ onc.2010.309; published online 9 August 2010

After the publication of the article, the authors noticed a minor error in Figure 1a panel 1 (MUC4 confocal image switched between SKOV3-Vector and SKOV3-MUC4). The authors would like to apologize for this mistake. The correct figure is reproduced below.

a

SKOV3-Vec SKOV3-MUC4
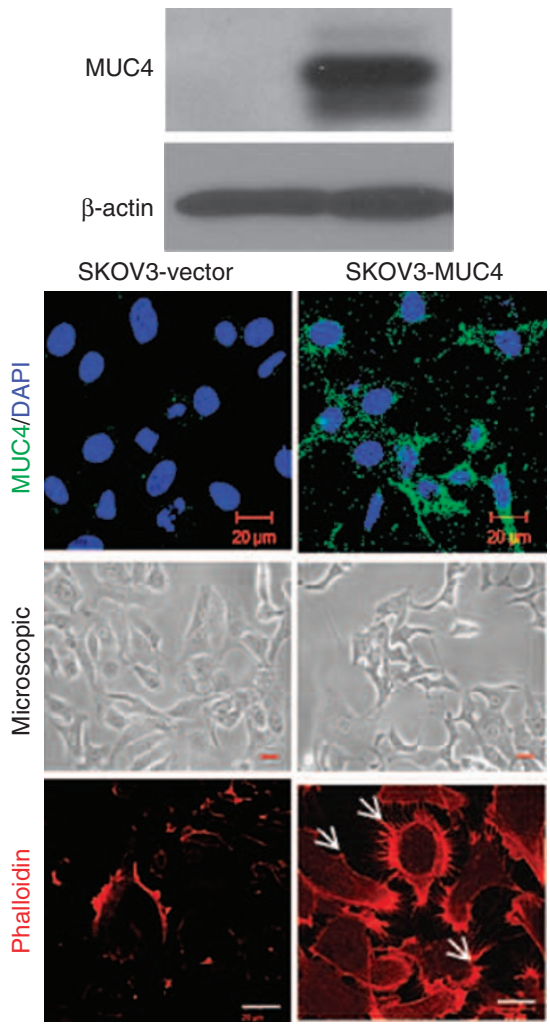

Figure 1 